\title{
Luminal composition and maturation of spermatozoa in the genital ducts of the African elephant (Loxodonta africana)
}

\author{
R. C. Jones \\ Department of Biological Sciences, The University of Newcastle, New South Wales, \\ Australia 2308
}

\begin{abstract}
Summary. The mean spermatocrit and sodium, potassium and protein concentrations of fluid collected from the rete testis of the elephant were similar to values described for the ram. Sperm maturation, as assessed by the location of the cytoplasmic droplet in the middle piece, occurred in the distal head and the isthmus of the epididymis (middle segment). Spermatocrit determinations indicated that $96 \%$ of the fluid leaving the testis was reabsorbed by the efferent ducts and proximal initial segment, and $53 \%$ of the remainder was reabsorbed in the more distal parts of the head of the epididymis (initial and proximal middle segments). Sodium was reabsorbed in the same concentration as luminal fluid and not in amounts equimolar with potassium. The potassium concentration increased from 12.1 mequiv./1 in rete testis plasma to 64.8 mequiv./1 in the proximal head of the epididymis. About two thirds of the protein in rete testis fluid $(3.8 \mathrm{mg} / \mathrm{ml})$ was reabsorbed by the efferent ducts and more was absorbed by the head of the epididymis.
\end{abstract}

\section{Introduction}

The structure and function of the genital tract of the bull elephant is of particular interest to comparative physiologists because the gonads and the genital ducts are located deep within the abdominal cavity and because of the elephant's immense size and relatively unspecialized habitat. Structural studies (Holt, Jones \& Skinner, 1980; Jones \& Brosnan, 1980) have shown that the excurrent ducts from the testes are, like those of scrotal mammals (Glover \& Nicander, 1971), structurally differentiated into an anatomically distinct head, body and tail and a histologically distinct initial, 'middle' and terminal segment. However, the ducts differ from those in scrotal mammals in a number of ways: the tail of the elephant epididymis is proportionally smaller than in scrotal mammals, such as the rat, rabbit and ram, and the elephant epididymis is thrown into folds (villi) in the initial and terminal segments. Furthermore, in the elephant most of the extragonadal spermatozoa are located in the head of the epididymis (Jones, Rowlands \& Skinner, 1974) and not in the tail as in ram (Chang, 1945) and rabbit (Orgebin-Crist, 1968).

The studies described in this paper were carried out to determine the site of maturation of spermatozoa and the protein and cation composition of the genital duct laminal fluids, thus aiding interpretation of the structural findings and providing a basis for comparison with other species. 


\section{Materials and Methods}

The epididymal material was collected from elephants which were slaughtered to avoid overstocking in the Kruger National Park, South Africa (Jones, 1973). Blood was collected from the carotid and jugular vessels before evisceration immediately after death. The testes and genital ducts were removed and partly dissected from the supporting mesentery in order to obtain access for sampling. The sampling began about 15 min after death. The same identification of sampling sites (Text-fig. 1) was used as in previous studies (Holt et al., 1980; Jones \& Brosnan, 1980). In addition, samples were collected where the extratesticular rete testis was sectioned from the testis (rete testis fluid) and at the distal end of the anatomical isthmus of the epididymis (asterisk, Text-fig. 1).

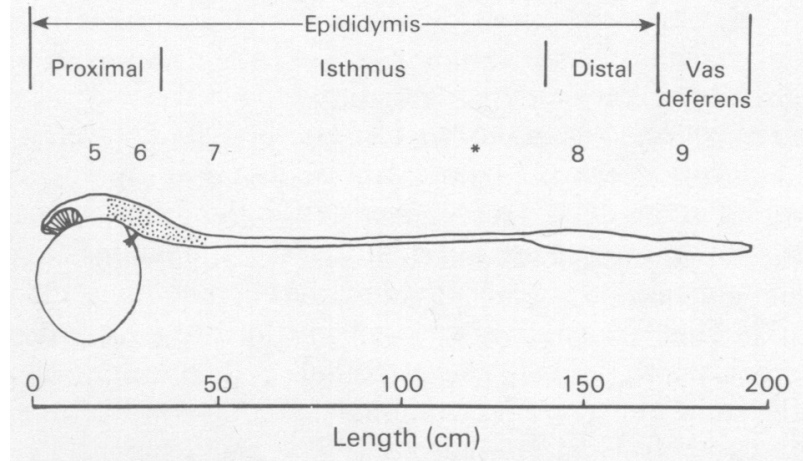

Text-fig. 1. A scale diagram of the elephant testis and genital ducts as they appear in situ. The efferent ducts are indicated by the shaded area above the testis and the 3 anatomically distinct regions of the epididymis are indicated. The stippled area shows the transitional zone (middle segment) between the histologically distinct initial and terminal segments. The numerals and asterisk identify the sampling sites.

Eosin-nigrosin smears (Blackshaw, 1955) of epididymal spermatozoa were prepared during July 1974. At each sample site the epididymal duct was sectioned with a scalpel in several places, the epididymis was squeezed and the exudate was collected with a Pasteur pipette. It was then mixed with a drop of eosin-nigrosin on a microscope slide and smeared. The slides were air dried and mounted in D.P.X. (B.D.H. Chemicals Inc., Poole, England). A total of 100 spermatozoa was examined under the light microscope and scored according to whether the cytoplasmic droplet was adjacent to the head (proximal), migrating along the middle piece (middle), adjacent to the principal piece (distal) or absent.

Luminal samples for chemical analysis were collected during September 1977. The sampling pipettes were prepared by drawing out the end of a $50 \mu$ l micropipette (Corning Ltd, Stone, England) and breaking the tip short. Paraffin oil (Fisher Scientific Co., Fair Lawn, U.S.A.), saturated with twice-distilled water, was loaded into the pipette before and after the luminal fluid to prevent it from dehydrating. At each site the luminal fluid, free of blood and interstitial fluid, was collected into a pipette after slitting the epididymal duct half way through. For the more proximal sampling sites it was usually necessary to repeat this procedure at several points within the sample area in order to collect sufficient fluid. After sampling, the pipette was hermetically sealed with a propane flame and centrifuged for $10 \mathrm{~min}$ at $1500 \mathrm{~g}$. Spermatocrits were estimated as the ratio of length of packed spermatozoa :length of packed spermatozoa plus plasma.

Plasma samples for cation analysis were stored (because of official requirements) in $50 \mu \mathrm{l}$ of $3 \%(\mathrm{w} / \mathrm{v})$ formaldehyde under $0.2 \mathrm{ml}$ water-saturated paraffin oil in hermetically sealed $1-\mathrm{ml}$ capacity Pyrex ampoules. The formaldehyde solution was prepared by depolymerizing paraformaldehyde in twice-distilled water at $60^{\circ} \mathrm{G}$ and neutralizing with ammonium hydroxide. 
Samples of formaldehyde solution containing no plasma were also stored for cation determination. For analysis, $1 \mu \mathrm{l}$ of the diluted plasma was diluted into $1 \mathrm{ml}$ swamping solution and assayed using an atomic absorption spectrophotometer. The swamping solution was $2 \mathrm{mg}$ potassium chloride $/ \mathrm{ml}$ for the sodium determinations and $1 \mathrm{mg}$ cesium chloride $/ \mathrm{ml}$ for the potassium determinations. Plasma samples for protein analysis were stored under oil in $50 \mu \mathrm{l}$ $1 \mathrm{~N}$-sodium hydroxide. Protein concentration was determined by the method of Lowry, Rosebrough, Farr \& Randall (1951). The results of the cation and protein determinations are expressed as concentrations in the original samples of plasma (Table 2).

Each study was a randomized block design where one animal represents a block and comparisons between sampling sites were made within the same reproductive tract. Analyses of variance were used to determine the statistical significance of differences between sites. The residual variance (interaction of blocks and sampling sites) was used as the denominator in the F-tests and to calculate the standard errors shown in Tables 1 and 2. However, as two samples were lost during the cation analyses the variance between animals, within sample site, was used as the estimate of random error for these measurements.

The net fluid movement from the duct lumen to the interstitium between any two sampling sites (subscripts 1 and 2 refer to proximal and distal sites respectively) was determined from the estimates of spermatocrit (S) and solute concentration (C). Positive values for absorption indicate net movement out of the epididymal duct and negative values indicate net movement into the duct. The values estimated are listed below.

(1) The volume of absorbate expressed as a percentage of the total volume of luminal fluid (i.e. spermatozoa + plasma) at the proximal sampling site $(=100-100 \mathrm{R})$ where

$$
1-\mathrm{R}=1-\mathrm{S}_{1} / \mathrm{S}_{2}
$$

(2) The volume of fluid not absorbed expressed as a percentage of the volume of luminal plasma at the proximal sampling site $\left(=100 \mathrm{R}^{1}\right)$ where

$$
R^{1}=\left(S_{1} / S_{2}-S_{1}\right) / 1-S_{1}
$$

Separate denominators were used to estimate $R$ and $R^{1}$ respectively in order to express transport across the duct walls in terms of the total luminal contents (referred to as luminal fluid $=$ spermatozoa + plasma) and just the plasma component (i.e. the source of absorbate).

(3) The amount of solute in the absorbate expressed as a percentage of the amount in the luminal plasma at the proximal sampling site as

$$
100\left(C_{1}-R^{1} C_{2}\right) / C_{1}
$$

(4) The concentration of solute in the absorbate as

$$
\left(\mathrm{C}_{1}-\mathrm{RC}_{2}\right) / 1-\mathrm{R}
$$

\section{Results}

Table 1 shows the location of the cytoplasmic droplet in spermatozoa sampled along the epididymis and vas deferens. Most of the droplets were located adjacent to the head of spermatozoa sampled from the initial segment (sites 4 and 5), a high proportion was mid-way along the middle piece of spermatozoa sampled from the middle segment (higher at site 6 than site 7) and droplet migration was complete in spermatozoa sampled from the terminal segment (site 8) and vas deferens (site 9). The proportion of spermatozoa with no cytoplasmic droplets was not statistically different for the 9 sample sites.

The spermatocrits shown in Table 2 indicate that $96 \%$ of the fluid leaving the testis was reabsorbed by the efferent ducts and the initial segment proximal to site 5 . About $53 \%$ of the 
Table 1. Location of the cytoplasmic droplet on the middle piece of elephant spermatozoa collected from sites 4 to 9 (see Text-fig. 1)

\begin{tabular}{ccccc}
\hline & \multicolumn{4}{c}{ Location of cytoplasmic droplet } \\
\cline { 2 - 5 } Sample site & Proximal & Middle & Distal & No droplet \\
\hline 4 & 91.0 & 2.0 & 0.2 & 6.8 \\
5 & 87.2 & $6 \cdot 6$ & 3.0 & 3.2 \\
6 & 29.8 & 30.2 & 36.4 & 4.0 \\
7 & 4.6 & 22.6 & 66.6 & 6.2 \\
8 & 3.2 & 3.8 & 89.9 & 8.2 \\
9 & 3.8 & 2.2 & 86.4 & 1.8 \\
\hline
\end{tabular}

Values are mean percentages for samples from 5 animals.

Table 2. Composition of luminal fluids from the rete testis and epididymis of 4 elephants

\begin{tabular}{|c|c|c|c|c|c|}
\hline & $\begin{array}{c}\text { Spermatocrit } \\
(\%)^{*}\end{array}$ & $\underset{\text { (mequiv./1) }}{\text { Sodium }}$ & $\begin{array}{l}\text { Potassium } \\
\text { (mequiv./l) }\end{array}$ & $\begin{array}{l}\mathrm{Na}: \mathrm{K} \\
\text { ratio }\end{array}$ & $\begin{array}{l}\text { Protein } \\
(\mathrm{mg} / \mathrm{ml})\end{array}$ \\
\hline Rete testis & 1.2 & $122 \cdot 3$ & $12 \cdot 1$ & $10 \cdot 3$ & 3.8 \\
\hline \multicolumn{6}{|l|}{ Epididymis } \\
\hline Site 5 & $26 \cdot 3^{a}$ & $114.8^{+}$ & $64.8^{\mathrm{a}} \dagger$ & $1.8^{\mathrm{a} \dagger}$ & $39 \cdot 2^{\mathrm{a}}$ \\
\hline 6 & $56.0^{\mathrm{b}}$ & 111.5 & $40.9^{b}$ & 2.9 & 52.7 \\
\hline 7 & $46 \cdot 0$ & $96 \cdot 2$ & $40 \cdot 0$ & $2 \cdot 5$ & $29 \cdot 3^{\mathrm{c}}$ \\
\hline * & 47.0 & 104.9 & $36 \cdot 4$ & $3 \cdot 0$ & $26 \cdot 5$ \\
\hline 8 & $50 \cdot 3$ & $102 \cdot 8$ & $37 \cdot 2$ & $2 \cdot 8$ & $36 \cdot 3$ \\
\hline s.e. of the means & 5.7 & 5.9 & 4.6 & 0.6 & 4.5 \\
\hline
\end{tabular}

a-c Significantly different from mean for more proximal site: $a, P<0.05 ; b, P<0.01 ; c, P<0.001$.

* A spermatocrit of $50 \%$ corresponds to a concentration of about $3.5 \times 10^{9} \mathrm{spermatozoa} / \mathrm{ml}$.

$\dagger$ Means from 2 elephants.

remaining fluid was absorbed between sites 5 and 6 , producing a total reabsorption proximal to site 6 of $98 \%$ of the fluid leaving the testis. The decrease in spermatocrit between sites 6 and 7 was consistent for all replicates, but it was not statistically significant. It corresponds to a $22 \%$ increase in epididymal fluid volume between the sites (or an increase from 2.1 to $2.6 \%$ of the epididymal fluid leaving the testis). The spermatocrits of samples taken at sites 7 to 8 were not significantly different, indicating that there was little net fluid exchange across the epithelium along this part of the epididymis.

The concentration of sodium in the luminal plasma did not vary significantly along the genital ducts (Table 2) and it was calculated that sodium moved with water across the duct epithelium in the same concentration as it occurred in the luminal plasma. This corresponds to the removal between the rete testis and site 5 of $97 \%$ of the sodium present in rete testis plasma, and the removal between sites 5 and 6 of $73 \%$ of the sodium present at site 5 . Potassium was concentrated in the efferent ducts and proximal part of the initial segment of the epididymis (i.e. proximal to site 5). However, the concentrating effect was only about 5-fold compared with the approximately 20 -fold concentration of spermatozoa and it was estimated that about $82 \%$ of the potassium in the rete testis plasma must have been reabsorbed at a concentration of 10 mequiv./l. A further $70 \%$ of the plasma potassium present at site 5 was absorbed between sites 5 and 6: the potassium concentration in the absorbate was estimated to be 86 mequiv./l. Distal to site 6 the potassium concentration remained much the same. The change in potassium concentration along the duct caused a change in the ratio of sodium :potassium. The ratio was 
10.3 in the rete testis plasma, reduced to about one-fifth this value at site 5 and did not vary significantly distal to site 5 .

The mean ( \pm s.e.m.) protein content of blood plasma for the 4 elephants was $107.4 \pm 5.6$ $\mathrm{mg} / \mathrm{ml}$, which was much higher than in the genital ducts (Table 2). After accounting for the concentrating effect of fluid reabsorption between the rete testis and site 5 it was estimated that there was a net loss of $65 \%$ of the protein from the ducts between the two sampling sites. There was a further net loss of $62 \%$ of the protein present at site 5 between sites 5 and 6 , but little net exchange in protein between the interstitium and duct lumen distal to site 6 .

\section{Discussion}

Although post-testicular maturation of eutherian spermatozoa has been correlated with changes in structure, motility, surface and membrane properties, keratinization and physical properties (for reviews see Orgebin-Crist, 1969; Bedford, 1975), some eutherian mammals do not exhibit some of these changes (Bedford, Calvin \& Cooper, 1973; Bedford \& Calvin, 1974; Cooper \& Bedford, 1976). As some of the species variation may be related to the evolution of post-testicular maturation of spermatozoa the work on the elephant is of particular interest. The findings to date indicate that during epididymal transit elephant spermatozoa develop a mature motility pattern and acrosomal structure, undergo changes in the properties of the plasmalemma, and the cytoplasmic droplet migrates along the middle piece (Jones et al., 1974; Hanks, 1977; present study). Although work on other characteristics is required, it therefore seems that post-testicular development of spermatozoa in the elephant, like some other testiconda (Bedford \& Millar, 1978), can involve the full complement of maturational changes that occur in such scrotal mammals as the rabbit.

The finding that cytoplasmic droplet migration occurs during passage of spermatozoa through the distal head and proximal isthmus of the elephant epididymis confirms that this region of the epididymis has features similar to the middle segment of the mammalian epididymis, and the high spermatocrit in the distal region of the elephant epididymis indicates equivalence with the terminal segment (Glover \& Nicander, 1971; Jones \& Brosnan, 1980).

Considering the technical difficulties involved in collecting fluid from the elephant's genital ducts, it is reassuring that the values obtained are within the range of values found in samples from live animals of other species (Levine \& Marsh, 1971; Voglmayr, Waites \& Setchell, 1966; Tuck, Setchell, Waites \& Young, 1970). A direct comparison of the composition and osmolality of elephant rete testis plasma (R. C. Jones, unpublished) with samples collected by direct cannulation of the ram (Voglmayr et al., 1966) indicate that the values obtained are very similar.

The concentrations of cation in the elephant genital ducts were also within the range of values found in the genital ducts of the bull (Crabo \& Gustafsson, 1964), rat (Levine \& Marsh, 1971 ) and hamster (Jessee \& Howards, 1976). The values for the elephant are in agreement with data for the bull and rat in that the sodium concentrations were much the same in the testis and proximal caput epididymidis, but differ in that they show no reduction in concentration along the epididymis. A direct comparison between the elephant and the bull (Crabo \& Gustafsson, 1964) indicates that the increase in potassium concentration from the testis to the proximal epididymis and the subsequent reduction in concentration along the epididymis is much the same for both species. It would therefore seem that in the elephant sodium is the major cation removed from the proximal genital ducts, it is removed in a fluid isosmotic with luminal fluid and its movement across the epithelial membrane is not in equimolar amounts with potassium.

The protein concentration of rete testis plasma was in the same range as values found in samples collected by direct cannulation of the ram (Voglmayr et al., 1966) and confirms that the fluid contains only about $3 \%$ of the protein present in blood plasma. However, the elephant studies also show that a large proportion of the protein in rete testis fluid was reabsorbed by the 
efferent ducts and proximal part of the initial segment of the epididymis. This finding is in general agreement with data on the bull (Crabo \& Gustafsson, 1964) and is also supported by structural findings of organelles associated with intracellular digestion (Jones, 1977; Jones \& Brosnan, 1980 ) in the efferent ducts and epididymal epithelium.

The rates of fluid absorption found in these studies roughly correspond to values found in the bull (Crabo \& Gustafsson, 1964) and rat (see Tuck et al., 1970; Levine \& Marsh, 1971) and the maximum spermatocrit for the bull and the elephant was for sampling sites towards the distal caput epididymidis. The $22 \%$ increase in luminal fluid volume found between sites 6 and 7 in the elephant epididymis was consistent for all replicates so would probably have reached statistical significance if more elephants had been studied. Consequently, the increase is probably biologicalty significant and is certainly of interest as it corresponds to the $13 \%$ increase in fluid volume which occurs in roughly the same region (between the head and body) of the hamster epididymis (Jessee \& Howards, 1976).

I thank Professor J. D. Skinner, Mammal Research Institute, University of Pretoria, for encouragement, general support and hospitality, the staff of Kruger National Park for their generous help and hospitality, Mrs D. M. Rhodes, Mr R. Dieckmann and Mr J. Matheson for assistance, and the Council for Scientific and Industrial Research, South Africa, and the Australian Research Grants Committee for financial support.

\section{References}

Bedford, J.M. (1975) Maturation, transport, and fate of spermatozoa in the epididymis. In Handbook of Physiology. Male Reproductive System. Sec. 7, Vol. 5, pp. 303-318. Eds R. O. Greep \& E. B. Astwood. Am. Physiol. Soc., Washington, D.C.

Bedford, J.M. \& Calvin, H.l. (1974) Changes in -S-S- linked structures of the sperm tail during epididymal maturation, with comparative observations in sub-mammalian species. J. exp. Zool. 187, 181-204.

Bedford, J.M. \& Millar, R.P. (1978) The character of sperm maturation in the epididymis of the ascrotal hyrax, Procavia capensis and armadillo, Dasypus novemcinctus. Biol. Reprod. 19, 396-406.

Bedford, J.M., Calvin, H.I. \& Cooper, G.W. (1973) The maturation of spermatozoa in the human epididymis. J. Reprod. Fert., Suppl. 18, 199-213.

Blackshaw, A.W. (1955) Factors affecting the revival of bull and ram spermatozoa after freezing to $-79^{\circ} \mathrm{C}$. Aust. vet. J. 31, 238-241.

Chang, M.C. (1945) The sperm production of adult rams in relation to frequency of semen collection. $J$. agric. Sci., Camb. 35, 243-246.

Cooper, G.W. \& Bedford, J.M. (1976) Asymmetry of spermiation and sperm surface charge patterns over the giant acrosome of the Musk shrew Suncus murinus. J. Cell Biol. 69, 415-428.

Crabo, B.O. \& Gustafsson, B. (1964) Distribution of sodium and potassium and its relation to sperm concentration in the epididymal plasma of the bull. $J$. Reprod. Fert. 7, 337-346.

Glover, T.D. \& Nicander, L. (1971) Some aspects of structure and function in the mammalian epididymis. J. Reprod. Fert., Suppl. 13, 39-50.

Hanks, J. (1977) Comparative aspects of reproduction in the male hyrax and elephant. In Reproduction and
Evolution, pp. 155-164. Eds J. H. Calaby \& C. H. Tyndale-Biscoe. Australian Academy of Science, Canberra.

Holt, W.V., Jones, R.C. \& Skinner, J.D. (1980) Studies of the deferent ducts from the testis of the African elephant, Loxodonta africana. II. Histochemistry of the epididymis. J. Anat. 130, 367-379.

Jessee, S.J. \& Howards, S.S. (1976) A survey of sperm, potassium and sodium concentrations in the tubular fluid of the hamster epididymis. Biol. Reprod. 15, $626-631$.

Jones, R.C. (1973) Collection, motility and storage of spermatozoa from the African elephant, Loxodonta africana. Nature, Lond. 243, 38-39.

Jones, R.C. (1977) The nature of the barrier to autoimmunity in the excurrent ducts of the mammalian testis. In Immunological Influence on Human Fertility, pp. 67-86. Ed. B. Boettcher. Academic Press, Sydney.

Jones, R.C. \& Brosnan, M.F. (1980) Studies of the deferent ducts from the testis of the African elephant, Loxodonta africana. I. Structural differentiation. $J$. Anat. (in press).

Jones, R.C., Rowlands, I.W. \& Skinner, J.D. (1974) Spermatozoa in the genital ducts of the African elephant, Loxodonta africana. J. Reprod. Fert. 41, 189-192.

Levine, N. \& Marsh, D.J. (1971) Micropuncture studies of the electrochemical aspects of fluid and electrolyte transport in individual seminiferous tubules, the epididymis and the vas deferens in rats. $J$. Physiol., Lond. 213, 557-570.

Lowry, O.H., Rosebrough, N.H., Farr, A.L. \& Randall, R.J. (1951) Protein measurement with the folin phenol reagent. J. biol. Chem. 193, 265-275. 
Orgebin-Crist, M.C. (1968) Gonadal and epididymal sperm reserves in the rabbit: estimation of the daily sperm production. J. Reprod. Fert. 15, 15-25.

Orgebin-Crist, M.C. (1969) Studies on the function of the epididymis. Biol. Reprod., Suppl. 1, 155-175.

Tuck, R.R., Setchell, B.P., Waites, G.M.H. \& Young, J.A. (1970) The composition of fluid collected by micropuncture and catheterization from the seminiferous tubules and rete testes of rats. Pflügers Arch. 318, 225-243.

Voglmayr, J.K., Waites, G.M.H. \& Setchell, B.P. (1966) Studies on spermatozoa and fluid collected directly from the testis of the conscious ram. Nature, Lond. 210, 861-863.

Received 26 November 1979 